\title{
Comparing porosity and permeability measured from samples and estimated from logs in a SE- Brazil carbonate reservoir
}

Abel Carrasquilla1 \& Fernanda Tavares'1. 'Petroleum Engineering and Exploration Laboratory, Darcy Ribeiro Northern Rio de Janeiro State University, Km 163 Amaral Peixoto Highway, Brennand Avenue S/N, Imboassica, Macae-RJ, 27930-480.

\begin{abstract}
Copyright 2019, SBGf - Sociedade Brasileira de Geofísica
This paper was prepared for presentation during the $16^{\text {th }}$ International Congress of the Brazilian Geophysical Society held in Rio de Janeiro, Brazil, 19-22 August 2019.

Contents of this paper were reviewed by the Technical Committee of the $16^{\text {th }}$ International Congress of the Brazilian Geophysical Society and do not necessarily represent any position of the SBGf, its officers or members. Electronic reproduction or storage of any part of this paper for commercial purposes without the written consent of the Brazilian Geophysical Society is prohibited.
\end{abstract}

\section{Abstract}

In this study, a carbonate reservoir was evaluated with the use of geological information, geophysical well logs and laboratory data. The reservoir is in the post-salt layer of Campos Basin - Southeast Brazil The greatest difficulty in characterizing this type of reservoir is that the carbonates present a great variation in their physical properties and, therefore, it is convenient to divide the reservoir into zones according to their different petrophysical characteristics. Based on basic logs, the work determined parameters such as porosity, permeability, irreducible water saturation, top and bottom of the reservoir, oil/water contact and hydrocarbon producing zones. In this sense, nuclear magnetic resonance was also used to obtain the total porosity along the well and the permeability was estimated using Timur, Coates and, Schlumberger approaches. Subsequently, these results were compared with laboratory data and basic log estimates. We conclude that the empirical methods are efficient and facilitate the evaluation of carbonate reservoirs, but should be done with caution, since these estimates are very preliminary.

\section{Introduction}

This petrophysical study was carried out in a carbonate reservoir of the Campos Basin, which is located along the continental shelf of Rio de Janeiro State in Southeast Brazil (Figure 1). The oil reservoirs are found in almost the whole stratigraphic column of this basin with fractured basalt, coquinas, turbidites and carbonaceous rocks as the main sequences. The carbonate reservoir was formed during the Albian, when the marine conditions succeed, giving rise to a platform of the restricted marine basin phase known as the Macae Group (Figure 2). This group includes ramp deposits which constitute rocks of different textures, such as porous grainstones and packstone, as well as external platform shale (Bruhn, 1998).

To characterize the petrophysical properties of carbonate reservoirs, as porosity and permeability, the interpretation of logs and the evaluation of samples of rocks in the laboratory are the most used methods, in order to discover the affinity between these parameters in this type of reservoirs (Aguilera \& Aguilera, 2001). The resolution and spatial coverage of these two methodologies, combined with the measured and estimated parameters, produce different scales to obtain lithological and structural information in subsurface (Shenawi et al., 2007). Therefore, our study explores the virtues of these techniques, including the addition of geological interpretation, to evaluate, from a petrophysical point of view, a set of data from a carbonate deposit in the Campos Basin, determining the reliability of the estimates of the porosity and the permeability.

\section{Methodology}

To develop this work, the initial data set of caliper (CAL), gamma ray (GR), density (RHOB), resistivity (RT), neutron porosity (NPHI) and sonic (DT) basic logs, along with the NMR log, were plotted and analysed. The analysis includes data processing, which consisted of the preparation of data to eliminate the spurious. Next, the basic profiles were used to characterize the reservoir. The porosity and laboratory permeability data were used to zonate the reservoir. Continuing, the porosity and the permeability were obtained from the empirical models with the well profiles. These estimates were then compared with laboratory experimental data. Finally, considering the results, the conclusions were reached.

Thereafter, different porosity values were computed and plotted using the equations shown in the Table 1, as also, compared with porosity experimental data. According to these results, a multiple linear regression, that includes all the porosity approaches mentioned above, was produced to accomplish a better fit with the laboratory data.

For the permeability, the procedure was very similar to the porosity. First, different permeability values were computed and plotted using the equations presented in the Table 2, as also, compared with permeability laboratory data. Having in hand such results, a multiple polynomial regression, that includes all the permeability approaches mentioned before, was made to achieve a better adjust to the observational data.

\section{Results}

Figure 3 shows depth (track 2) and the basic GR (track 1), RT (track 10) and NPHI - RHOB (track 11) logs, which were used in this work to characterize the reservoir. This figure also shows the lithological and borehole data (tracks 3 and 9, rock sample analysis, tracks: 3-cores, 4texture, 5-granulometry, 6-oil presence, 7-facies, 8-facies and 9-petrophysical units). In this figure, the zones of packstone, grainstones and cemented grainstones also appear clearly distinguished. Finally, the experimental measurements of $\phi$ and $\mathrm{k}$ in laboratory are shown in tracks 12 and 13, respectively (Carrasquilla et al., 2012).

The GR log registered values of $75-150^{\circ} \mathrm{API}$ up to X05 to $\mathrm{X} 20 \mathrm{~m}$ depth, caused mainly by the presence of $U$ in 
marl (track 2), whereas between X21 and X49 m it has $30^{\circ}$ API caused by the carbonate. The RXO and RT logs present low and overlapping values at depth x25 which characterize an impermeable formation as marl (track 3 , Figure 4). Between X25 and X30, this difference is most prominent with values up to 2000 ohm.m, which characterizes the presence of hydrocarbons in a permeable formation. The oil-water contact is marked by a decrease in the resistivity at depth $X 40 \mathrm{~m}$ and, hence, the resistive logs have low values up to $1.0 \mathrm{ohm} . \mathrm{m}$ which shows the presence of brine. The NPHI and RHOB logs show a separation and a cross-over indicating the presence of gas due to the increase in NPHI apparent porosity (24 to $32 \%$ ) and a decrease in the RHOB log (2.4 to $2.2 \mathrm{~g} / \mathrm{cm}^{3}$ ). In addition, the crossing of these logs (yellow shadow) shows the limits of the reservoir, which provides a qualitative prediction of the upper part and the base between X20 and X50 m (track 11, Figure 3 and track 4, Figure 4).

Figure 5 (track 4) shows the porosity laboratory measurements $\phi L A B$ (PETRO:POROS, blue dots), together with the multiple linear regression (MLR) for $\phi M L R-N M R$ (MLRnmrPHIT, red curve) and total porosity $\phi T$ NMR (NEL:PHIT, black curve). MLR:T2cutoffpoco was used to generate $\phi$ MLR-NMR (track 4), using a standard cutoff value of $100 \mathrm{~ms}$ for carbonates (track 5, red curve), while LWD:T2LM (yellow curve) was used to generate $\phi$ TNMR, using the mean geometric cut-off the T2 distribution. The $\phi$ T-NMR curve is shifted to the right of $\phi\llcorner A B$, while the QMLR-NMR curve to the left (track 4). This can be related to the chosen cut-off in the T2 relaxation distribution (T2DIST), which can be selected between the mobile fluid (FFI, also called BVM, hydrocarbons plus water), water and immovable fluids (BVI) and clay-bound-water (CBW). However, both approaches follow the shape of the experimental porosity curve.

Figure 6 (track 5) presents the permeability laboratory measurements KLAB (PETRO:Perme_n, blue dots) and the permeability obtained using Coates approach (kCOATES= $(\phi T / \mathrm{c})^{\mathrm{a}}(\mathrm{BVM} / \mathrm{BVI})^{\mathrm{b}}, \mathrm{MLR}: \mathrm{nmrPermpoço}$, red curve) is also presented, where $\phi \mathrm{T}=\phi \mathrm{T}-\mathrm{NMR}$, and, $\mathrm{a}=4, \mathrm{~b}=2$ and $6<\mathrm{c}<15$ are empirical constants. MLR: PermeaSDR_mlr (green curve) was obtained from the Schlumberger Doll Research approach ( $\mathrm{kSDR}=\mathrm{b} \phi \mathrm{T}^{\mathrm{m}} \mathrm{T}^{2}{ }_{2 \mathrm{gm}}$ ), where $\phi \mathrm{T}=\phi \mathrm{T}$-NMR, T2gm is the T2 distribution mean geometric cut-off and $b=4$ and $m=4$ are dependent empirical variables of geological formation. Still, PermealA (black curve) was obtained by Timur approach ( $\mathrm{K}_{\mathrm{TIMUR}}=\mathrm{a}\left(\phi \mathrm{T}^{\mathrm{b}}\right) / \mathrm{S}_{\mathrm{WIRR}}$ ), where SwIRR is the irreducible water saturation, and, $a=10, b=4.4$ and $C=2$ (Coates et al., 1999). Analysing these results, we can see that KSDR and KCOATES have a similar behaviour in the whole reservoir, having overlapped in some depths. kTIMUR, instead, presents a marked deviation of the laboratory data in some depths. In a general way, all the permeability estimates maintain a similar distribution pattern, where the worst values appear in the packstones and cemented grainstones, while the best fit to experimental data is in the sector of the grainstones.

\section{Conclusions}

The reservoir was divided into packstone, grainstone and cemented grainstone sectors based on a stratigraphic control determined from laboratory tests and log data. The grainstone zone was considered with the best petrophysical properties because it has the highest values of porosity and permeability. On the other hand, kSDR showed a wide variation in relation to the $T_{2}$ distribution cut-offs, which is more related to the porosity input. When comparing NMR estimates and laboratory data, kCOATES and kTIMUR show, respectively, the best and the worst fit with the experimental data. This result can be attributed to a better tuning made to the parameters of the Coates empirical method, what takes a close estimate of true permeability. This shows that when NMR is used in a quantitative assessment of permeability the estimate must be accepted with caution because it is predominantly qualitative. Therefore, it is concluded that the methodology used in this work is efficient and facilitates the carbonate reservoir evaluation, with the NMR log contributing positively for a good petrophysical characterization.

\section{Acknowledgements}

We thank Petrobras for the financial resources to develop a research project and for the release of the data set, and $\mathrm{CNPq}$ for the research grant and UENF - LENEP for its facilities and computational infrastructure.

\section{References}

Aguilera, R. and Aguilera, M. 2001. The integration of capillary pressures and Pickett plots for determination of flow units and reservoir containers. SPE Annual Technical Conference and Exhibition held in New Orleans, Paper 71725.

Bruhn, C.; Gomes, J.; Lucchese Jr., C. and Johann, P. 2003. Campos Basin: reservoir characterization and management - historical overview and future challenges. Offshore Technology Conference. OTC 15220.

Carrasquilla, A.; Nocchi, G.; Briones, V.; Torres, M.; Franco Filho, N.; Schuab, F. \& Sanchez, P. 2012. Petrophysical studies in the characterization of carbonate reservoirs in Campos Basin - Brazil. Annals, AAPG/SPE/SEG Hedberg Research Conference, Fundamental Controls on Flow in Carbonates, Saint Cyr sur Mer, France.

Coates, G.; Xiao, L. and Prammer, M. 1999. NMR logging: principles and applications. Gulf Professional Publishing.

Nocchi, G.; Carrasquilla, A.; Filho, N. F. and Schuab, F. 2012. Evaluation of the carbonate reservoir of the field basin integrating laboratory data with well logs. V Brazilian Symposium on Geophysics, Salvador-BA. (In Portuguese).

Shenawi, H.; White, J.; Elrafie, E. and Kilany, K. 2007. Permeability and water saturation distribution by lithology facies and hydraulic units: a reservoir simulation case study. $15^{\text {th }}$ Middle East Oil \& Gas Show and Conference, Bahrain. Paper 105273. 


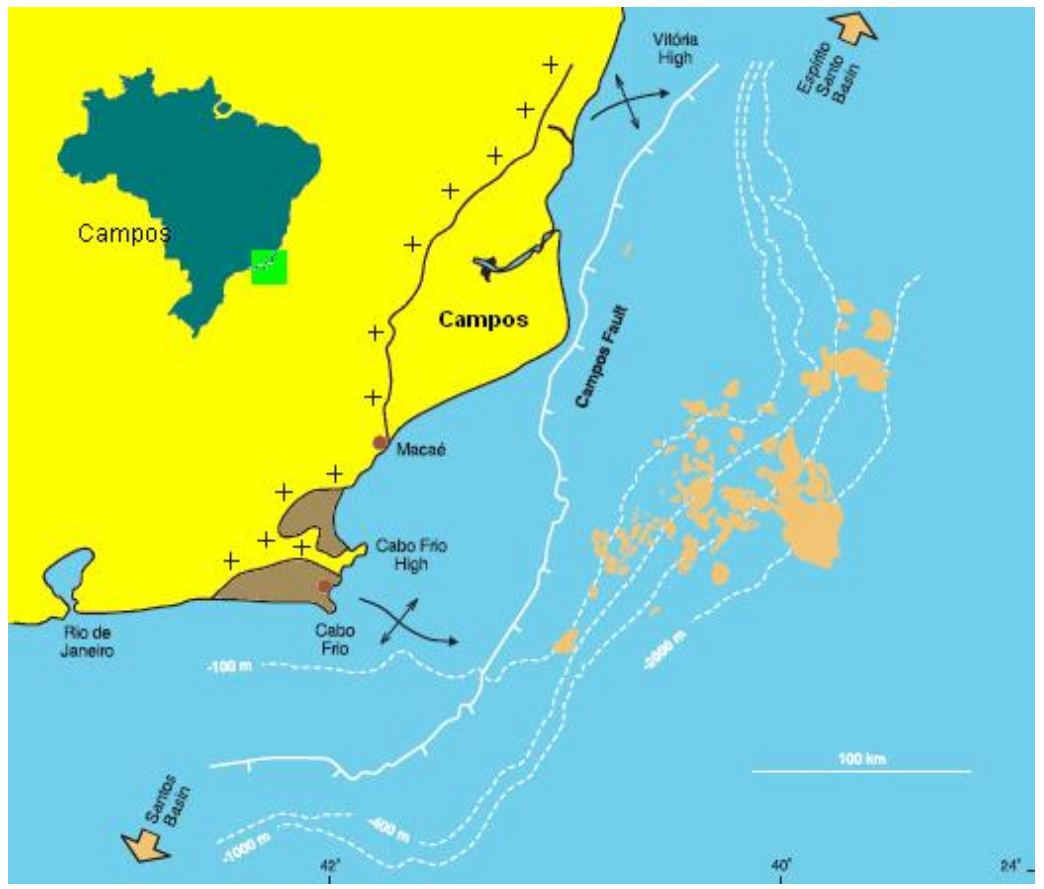

Figure 1. Campos Basin and its oil fields in orange (modified from Bruhn, 1998).

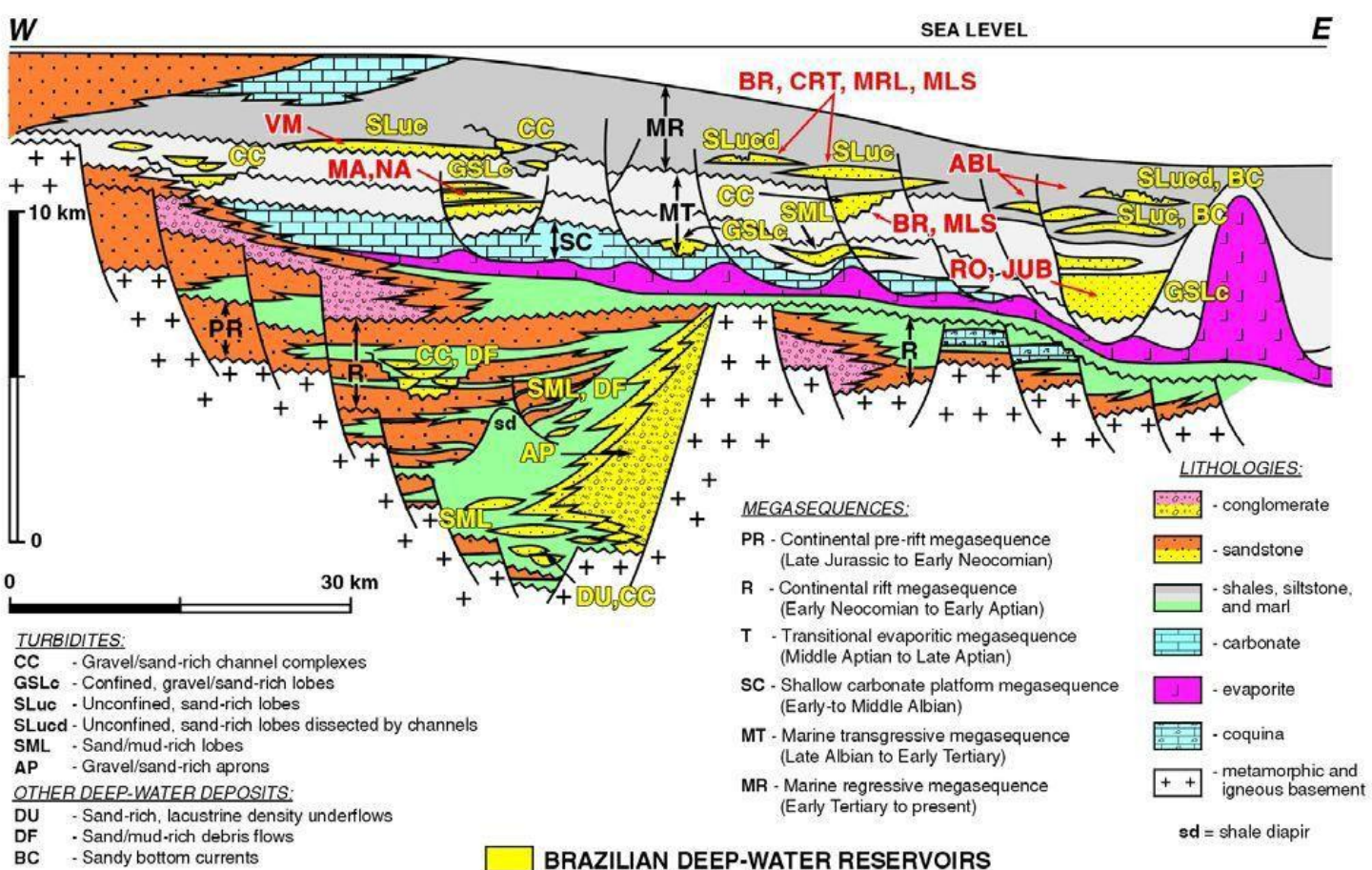

Figure 1. Typical geological section of the Campos Basin (modified from Bruhn, 1998). 


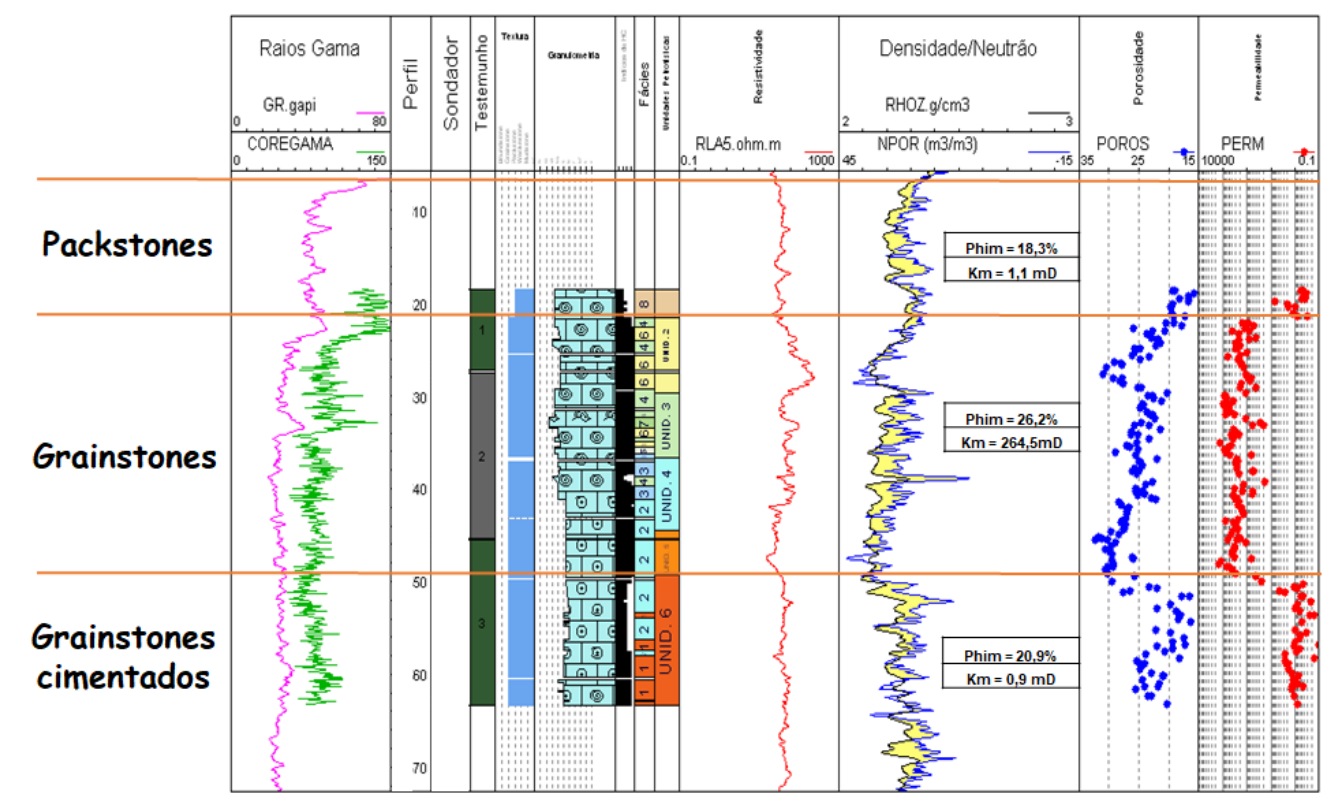

Figure 3. Campos Basin well, basic logs, tracks: 1-GR, 2-depth, 10-RT, and, 11$\mathrm{NPHI}$ and RHOB. Rock sample analysis, tracks: 2-cores, 3-texture, 4granulometry, 5-oil presence, 6-facies, 7-petrophysical units, 8-porosity and 9permeability experimental data (modified from Nocchi et al., 2012).

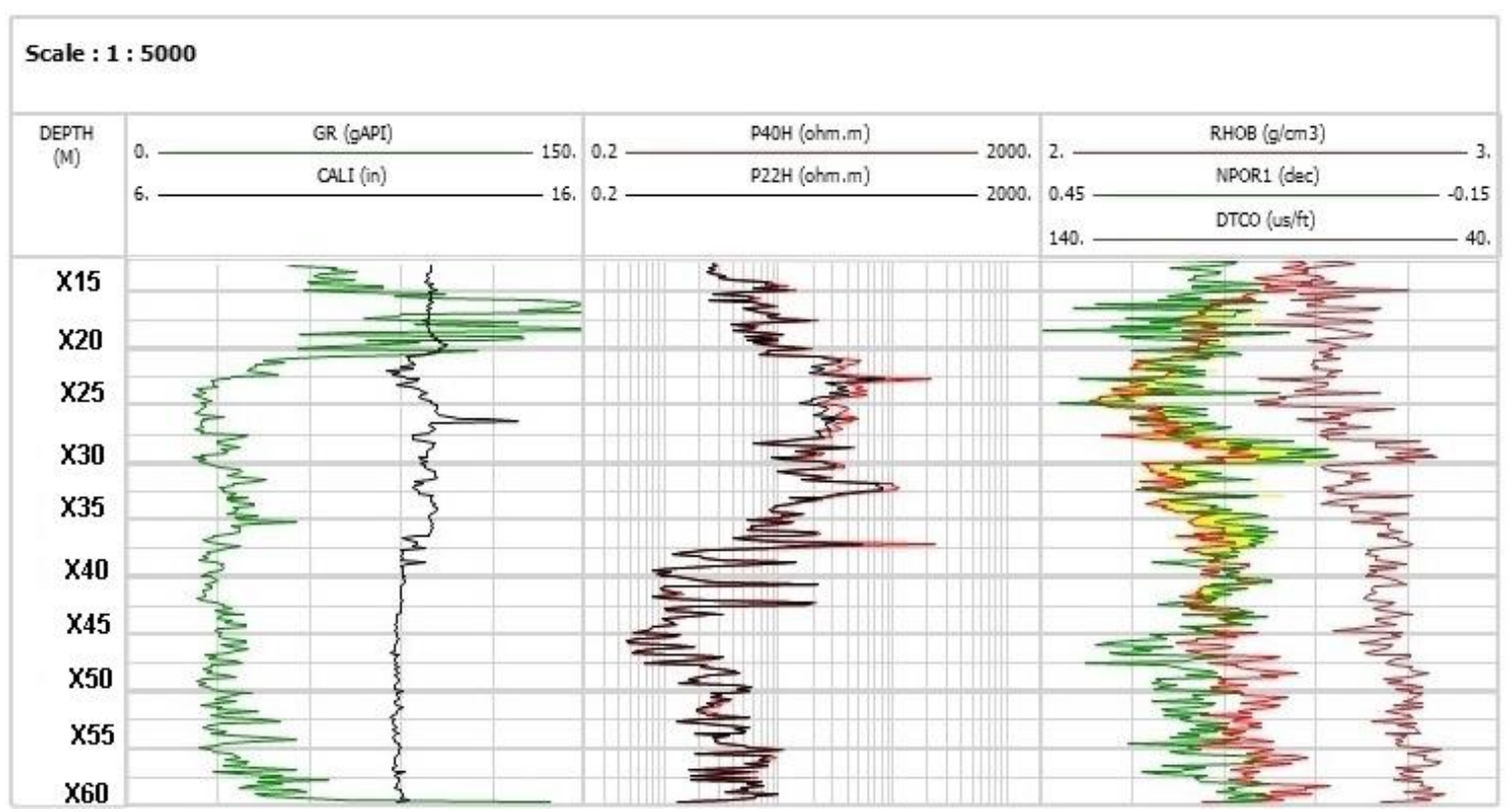

Figure 4. Campos Basin well, basic logs, tracks: 1-GR and caliper,2-RT and RXO, 4-NPHI, RHOB and DT (modified from Nocchi et al., 2012). 


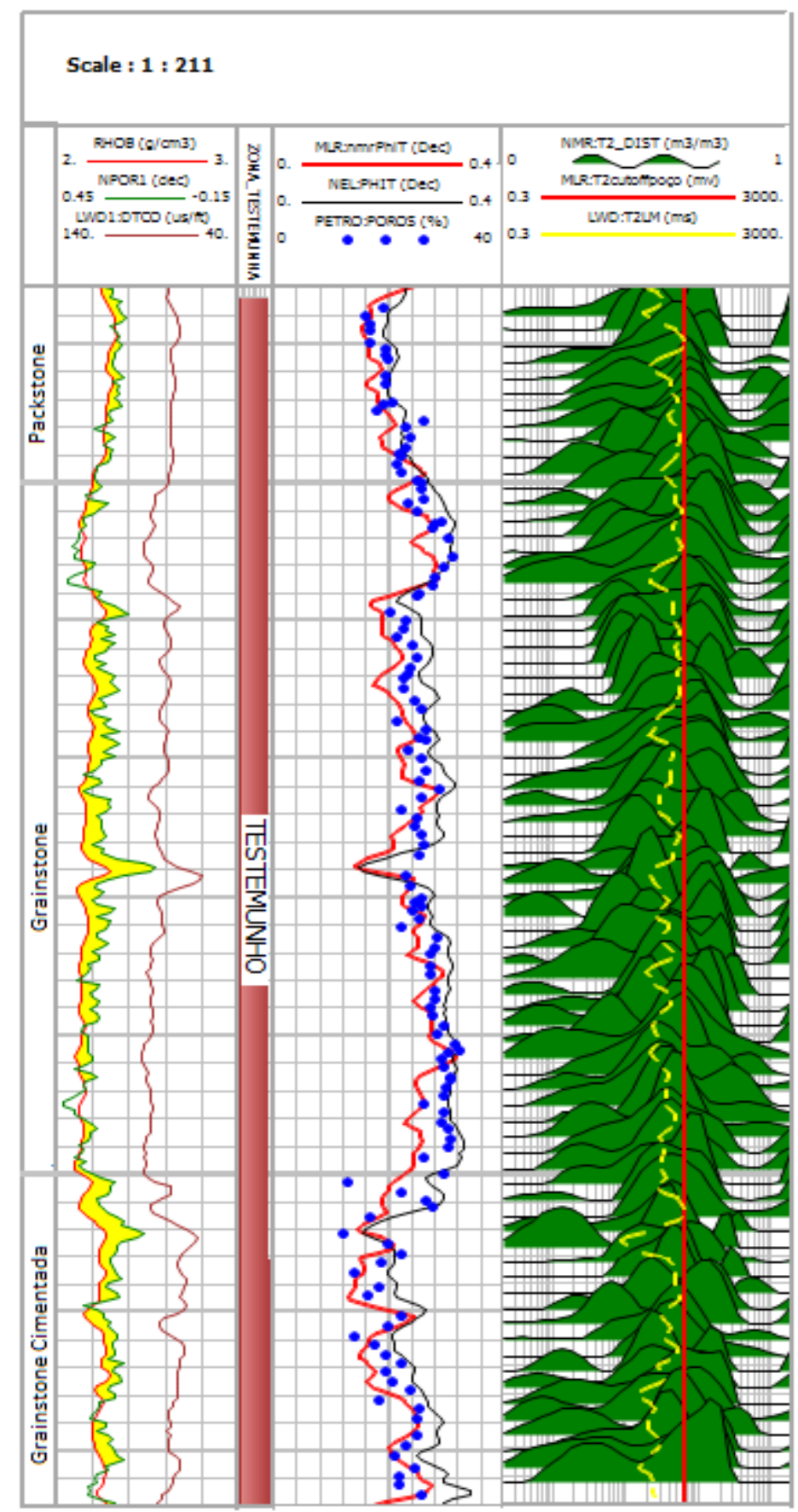

Figure 5. Tracks: 1-facies, 2-cores, 3-porosity: experimental data (blue dots), NMR total with multiple linear regression (red curve) and NMR total (black curve), 4-T2 distributions: linear (red) and geometric mean (yellow) cut-offs (modified from Nocchi et al., 2012). 


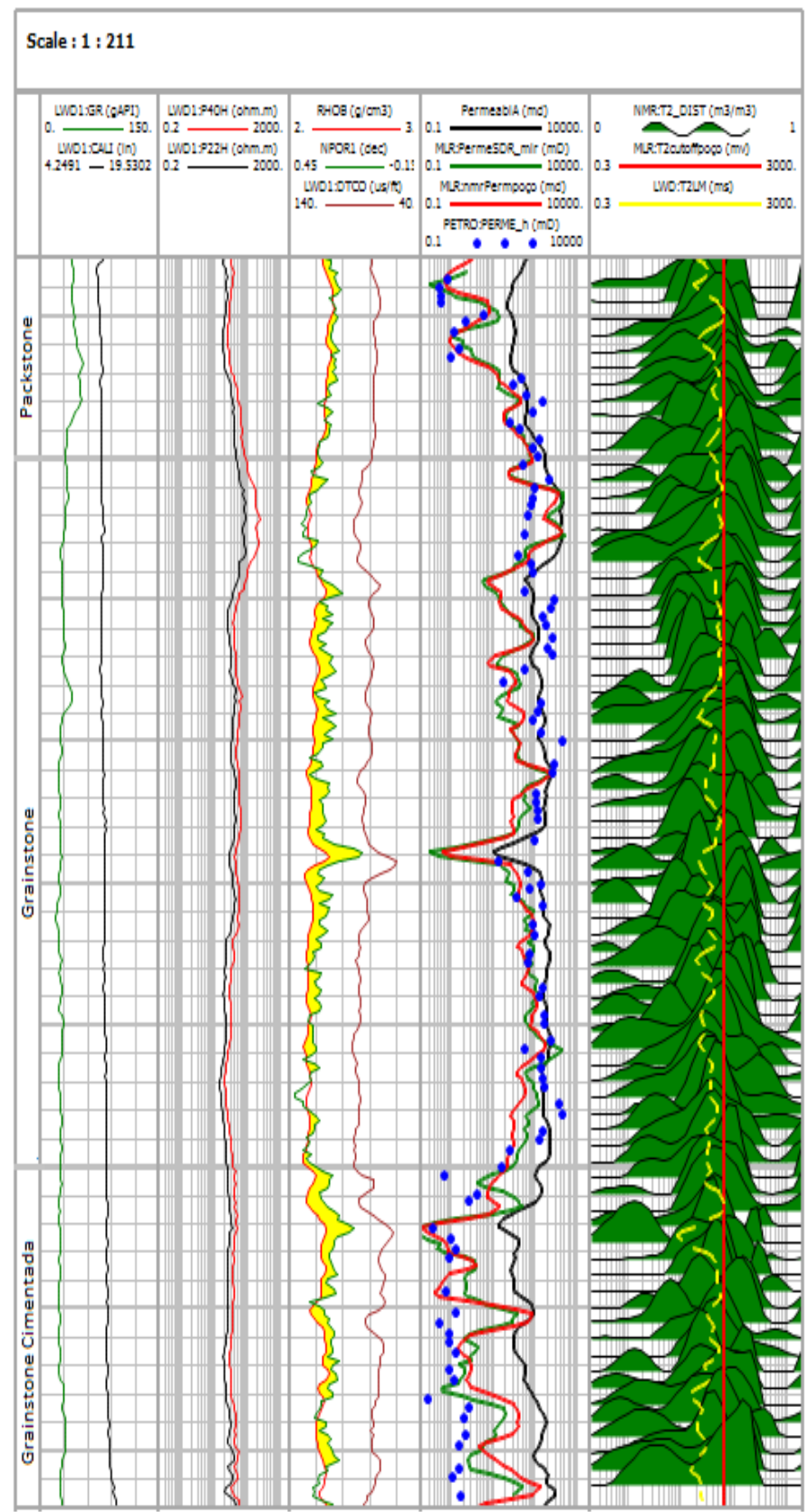

Figure 6. Tracks: 1-facies, 2-GR and caliper, 3-LWD RT and RXO, 4-NPHI, RHOB and DT logs, 5-permeability: experimental data (blue dots), MLR SDR (green curve), Timur (black curve), and, MLR Coates (red curve), 4-T2 distributions: linear (red) and geometric mean (yellow) cut-offs (modified from Nocchi et al., 2012). 